\title{
WHY DOES POPULISM HAVE A FUTURE?
}

\author{
Tania Glouhtcheva \\ PhD student at Sofia University "St. Kliment Ohridski", Sofia, Bulgaria \\ taniagl@abv.bg
}

\begin{abstract}
The following research aims to present Populism as a phenomenon and the reasons why it has a future all over the world. The $X X I$ - st century is also known as the "Populist era" (Cas Mudde). Both the left and the right have nothing more to offer and give the people who want something new. The change should also give them security. Populism has a future because it is not an ideology. It "borrows" the most appropriate from the left and the right ideologies and adjusts" them to people's problems and gives solutions. Populism is a global phenomenon. Today we are witnessing the 4-th wave which is spreading all over the world. The former 3 waves have been mainly in Latin America, the place which is also considered its cradle, as Ernesto Laclua argues. Many political scientists such as Cas Mudde, have warned about the threat of the rising Populism, at the beginning of the century, but nobody paid attention. Why is Populism becoming more and more popular? The main reason is that it constantly changes. It's different in every country and always has "the right solutions" to the different problems of the different societies. Hence, it aims not only those who don't sympathize any political party, but also those who are disappointed, have doubts and those who don't feel represented. Secondly, the populist leader is always close to the people: he dresses like them, understands their problems, walks among the people and doesn't have bodyguards. He doesn't need to say ï am one of you!" because it is obvious. The political scientists talk about "Left Populism" and "Right Populism". The first one is typical for countries with serious social problems - mainly in Latin America. Whereas the second type characterizes the countries with well-developed economies - in Western Europe and the USA.There are not many researches made about the Populism in Bulgaria. Political scientists start using the word in the last decade and it is applicable to all parties. Georgi Karasimeonov and Daniel Smilov, argue that Simeon Saxe-Coburg-Gotha is the first Bulgarian populist leader. Even after his government, the people still look for someone "to save" them, which only proves that Populism is not over and it is something useful because it brings hope.The used methods are: sociological research, taking interviews, analyzing data and deduction.

* The paper contains the author's personal researches, made in the University of Sao Paulo, in Brazil
\end{abstract}

Keywords: Populism; Left Populism; Right Populism; Ideology; Leader; Bulgaria; Latin America; Western Europe; USA. 


\title{
ЗАЩО ПОПУАИЗМЬТ ИМА БЪАЕЩЕ?'
}

\author{
Таня Глухчева \\ Аокторант на СУ „Св. КАимент Охрилски“, Софоия, България
}

\begin{abstract}
Резюме: АОк^аАьт има за цел Аа разглеАа популизмьт като феномен, както и причините, поради които той има бълеще в целия свят. XXI век е времето на популизма. Аявото и Аясното политическо пространство са се изчерпали и избирателите искат нещо ново. Искат сигурност и промяна. Популизмьт има бъдеще, защото сам по себе си не е илеология и не може да се изчерпи. Той взема „най-подходящото“, както от мевите, така и от Аесните илеологии, "прилага" ги към проблемите на народа и предлага
\end{abstract} начин за решението им. Популизмът е глобален френомен. Анес сме свАетели на неговата 4-та въ^на, която залива цял Свят. ПреАходните три са били Геогрорски съсреАоточени преАимно в Аатинска Америка, считана за негова родина, спореА политолога Ернесто Аакруа. Много Аруги изследователи на популизма, среА които Кас Муле, са посочили опасността от разпространяването му още в началото на века. В какво се изразява силата на популизма? Основната причина е, че той непрекъснато се променя взависимост от Аържавата, актуалните проблеми и исканията на обществото. Така обжваща не само безпартийните избиратели, но и раочарованите, колебаещите се и всички, които не се чувстват представени. Втората причина е, че популисткият милер е винаги среА народа: облича се като него, съпричастен е с проблемите му, не се притеснява $\Delta а$ ходи пеша и без охрана. Не е необходимо да изрича посланието „Аз съм еАин от вас!", защото то се вижАа. Учените разАелят популизма на "Аяв" и "Аесен“. Аевият е характерен за страни със сериозни социални проблеми предимно в Аатинска Америка. Аесният е присъщ на Аьржави със си^но развити икономики, затова се среща в Запанна Европа и САЩ. В България популизмът не е изслеАвам заАьлбочено Ао този момент. Терминът започва $\Delta а$ се използва през послеАното Аесетилетие и е приложим за всички партии. Политолозите Георги Карасимеонов и Ааниел Смилов считат, че популистката вълна в България запоява със Симеон Сакскобургтотски. СлеА неговото управление, избирателите пролулжават Аа тьрсят "спасител“, което показва, че популизмът не е изчерпан, а напротив - той е необхолим, защото носи наАежАа. Използваните методи са: социологическо проучване, вземане на интервюта, анализ и обработка на Аанни и АеАуктивен поАхоА.

*АОКАаАът е написан и с направени мични изслеАвания на автора, при обмен в Университета на Сао Пауло в Бразилия.

\footnotetext{
' Бел. рел.: Статията разглежАа Аискусионна тема и не ангажира редакционната колегия с тезите и становищата на автора. Съставителите са готови $А$ а публикуват и мруги мнения по темата.
} 
КАючови Ауми: популизъм, Аяв популизъм, Аесен популизъм, илеология, България, Аатинска Америка, Запанна Европа, САЩ

Кой е най-поАходящият момент за популизма? ПравиАният отговор на този въпрос, винаги ще бъле: „Сега!" СпореА Хеге^, за опрелелен вил политика се пише, когато тя не може $а$ б бъле приложена на практика. По същия начин се разпространява теория за революция, в момент, когато е невъзможно $а$ избухне.

Какво преАставлява „популизмьт“? За него се говори много през последното десетилетие, имайки предвиА, случващото се на световната политическа сцена. От него са засегнати, както икономически си^но развитите страни, так и развиващите се. Кьм момента освен Япония, има още няколко страни, където популизмьт не е известен.

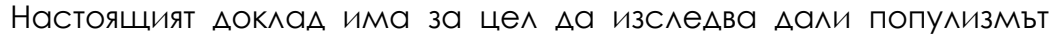
има бълеще, но за $\Delta$ a $\Delta$ a $\Delta$ е отговор на този въпрос е необхолимо $\Delta а$ се проследят корените му, причините за сьществуването му и защо става все по-предпочитан от избирателите. За целта се запознах с изследванията на най-виАните политолози като Кас Муле, Ернесто ^акруа, също така направих собствени проучвания по време на 4месечния ми престой в Южна Америка. Като Аокторант в „Университета на Сао Пауло“, имах възможността Аа общувам С местни изследователи на феномена "популизьм“ и да взема интервюта от ^атиноамериканци от всякаква възраст, профессия, социално положение и пол (Bremmer, 2018), (Celis, and Lovenduski, 2018), (Childs, and Dahlerup, 2018), (Clinton, 2017), (Dovi, 2018), (Etzioni, 2018), (Felix, and Glaser, 2018), (Ignatova, 2015), (Joignant, 2012), (Meret, and Siim, 2017). (Mudde, and Rovira-Kaltwasser, 2012), (Rico, Guinjoan, and Anduiza, 2017), (Sayer, 2016), (Smilov, 2008), (Teorell, Sum, and Tobiasen, 2007), (Wajner, 2019).

XXI век е времето на популизма, защото лявото и дясното пространство са изчерпани и избирателите искат нещо ново, искат сигурност и промяна. Всички изследователи на "популизма" се обеАиняват около слеАните твърАения:

1. Популизмьт представлява противопоставянето на честния, изстралал народ срещу корумпираните елити. 
2. Популистьт печели, защото успява $\Delta \mathrm{a}$ накара народьт $\Delta \mathrm{a}$ го чуе. Говори с кратки, точни, ясни фррази. Използва прости Ауми. Винаги е срел народа. Когато не е - използва съвременни средства за комуникация като социалните мрежи и най-предпочитаните медии.

3. Популизмьт сам по себе си не е илеология. Точно това го прави "Устойчив и изаръжлив във времето“. Той „взема“ най-подходящите за момента идеи от вече сьществуваща идеология/ сьществуващи илеологии. Непрекьснато се развива, налгражда, променя. Вьпреки това:

4. Различават се Ава виАа популизьм: ^яв и Аесен. Пьрвият е характерен за страни сьс сериозни социални проблеми: голямо неравенство межАу бедни и богати. Най-добър пример за това са страните в Аатинска Америка и по-конкретно Бразилия, Венецуела, Колумбия (в Бразилия например разликата между човек с минимална заплата и човек с максимална е 126 пьти. В Аания е само 5 пьти.). Презилентите им често са сочени за популисти - найвече тези, които преллагат мерки за намаляване на белността. Аесният популизъм е в страните със силно развита икономика, които често стават основна Аестинация на имигранти от по-беАни Аьржави. Затова Запална Европа и САЩ са „заляти“ от него. Неслучайно използвам метафрората „заляти от популизма“. За него не се говори като за различни етапи, а вълни. ИАват, заливат за известно време и си отиват, само, за да се върнат още по-мощни. Анес, според Кас Муде, сме свидетели на четвьртата и наймощната.

5. Основните характеристики на популистите са:

- Подходящ език, съобразен изцяло с избирателите. В случая с популистите те умело използват и повтарят множество пьти словосьчетанията: "корумпирани елити“, „престьпници имигранти" и Аруги.

- Убелителност - Аа създават вяра, без значение Аали религиозна, политическа или обществена, в Аело, мичност или иАея - в това се състои ролята на големите лилери.

- Обаяние -лично обаяние, харизма. 
Аржентинският изследовател на популизма, Ернесто ^аклоа в няколко своИ изслеАвания посочва, че популизмът воАИ началото СИ от Аатинска Америка. Аруги политолози твърАят, че той започва с фрермерските брожения в САШ през XVIII век. Напоследьк се говори за корените му още в Аревна Елала. Това има слеАното обяснение. Още в Аревността велики орилософои като Платон и Аристотел са се опитали $\Delta$ a $\Delta$ алат най-Аоброто опрелеление, най-Аобрите насоки за това каква

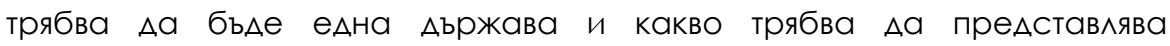
политиката. Първият преАлага илеалният вариант, Аокато вторият е попрагматичен. Амалгамата между политиката като теория и като практика никога не е била устойчива. Но намерението е важно, не резултатьт, както ни показват съвременните популистки милери. Още в Аревна Гърция всички са имали право на глас (с изключение на жените, децата и робите). Когато с течение на времето нещата започнали $\Delta а$ се променят - народьт започнал да слуша само тези, които му обещавали най-Аоброто.

Аристотел още в творбата си "Политика", посочва, че неправилното разпределение на благата ще доведе $А$ налигане на масите от еАна страна и/ или негодувание от страна на богатите, чието богатство се взема за раздаване на бедните. Според него така се ражАат най-големите престьпления - тези, породени от глаА или презаловоляване. Повечето са от второто. „Неравенството винаги е причина за революции", недоволство. Особено, когато не съществува никаква компенсация за жертвите. Съотнесено към Анешно време нещата се припокриват. Страни, за които неравенството е характерно, живеят в постоянен страх от народен бунт.

От Аруга страна П^атон Аопьлва: „много по-лесно е $\Delta а$ убеАиш тъ^пата, отколкото малка група хора". Затова народният гняв има сиАно влияние. Ако тълпата се налигне може да направи чудо, Аокато ако бъ $А$ убеден еАин еАинствен човек - това не води Ао никаква промяна. Това е още еАна причина и още еАно обяснение популистите $а$ не се стремят към определена група хора, подобно на традиционните партии и илеологии. Напротив, популистите целят посланията им Аа привлекат, колкото се може повече симпатизанти.

Какво ще стане, когато еАин популист Аойле на власт? Аали ще продьлжава да говори по същия начин или несъзнателно ще се 
превърне в това срещу, което се е бори^? Сократ отбелязва, че всеки, който Аойле навласт, рано или късно се превръща в това, срещу което се е борил. Не в нещо, което се Аоближава до собствените му илеи, а в точно противополжното. Защото властта корумпира хората Аори и с най-чистите намерения и полбули.

Колкото и Аа е трудно $а$ а се признае - всяка епоха има своите иАеИ и илеологии, които остават в историята заеАно с нея.

Така робството, крайнодесните, крайнолевите идеи нямат място в XXI век. Анес е времето на популизма. Ако елин политик иска $а$ б бъле

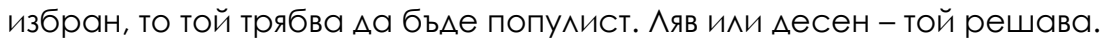

Защо популизмьт има бьлеще? СлеА проведена анкета и взети интервюта от латиноамерикански граждани и не само, подбрани на случаен принцип, на различна възраст, от различни профресии и пол, става ясно, че по-голямата част от населенито - почти 90\%, предпочитат презилент популист. Така се чувстват по-лобре представени. Например, в Бразилия, повечето хора Аори Анес, 10 голини по-късно биха избрали популистьт Аула Аа Силва преА неговата наслеАница Аимма Русефо и настоящият крайнодесен Болсонаро. Причината за това? По време на Авата си мандата, Аула, както хората имам навика $А$ а наричат, все енно им е близък приятел, съсеА, ролнина - е направил така, че

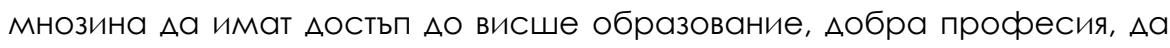
имат собствено жилище, кола. Рязко намалява процента на беАността. Аори и Анес $51 \%$ от чернокожото население има Аостьп $\Delta$ о висше образование, нещо немислимо при управленията преди него. Същото се отнася и за жените: Анес 54 \% от жените имат Аостьп Ао университет.

Аанните са от мичните ми изследвания, направени в Университета на Сао Пауло, в периода януари - март 2020 г. и се

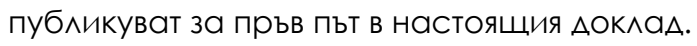

Пример за жена ^атиноамериканка и популист, презилент на голяма дьржава е Кристина Фернандес ле Кирхнер. Опрелеляна като

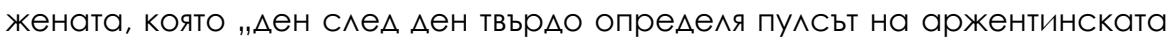
политика", тя винаги е в центьра на всички събития. Използва найценното си оръжие: думата. Известна е с пламенните си речи, понякога пробягва до агресивен тон. Интересното е, че когато мълчи, мьлчанието й има същата тежест. Винаги говори в пьрво Аице и е напьлно убелена, в това, което казва, аргументира, напала или защитава. В течение на 
мандата й, се преврьща в господар на словото. Има невороятна памет за събитията, но винаги ги описва по начин, по който нейната фригура $\triangle а$ изпькне. Описва ужасите от миналото, които заплашват $\Delta а$ се върнат в бълеще.

Също така може да говори за неща, които никога не са се случвали подчертано реалистично и по този начин обърква опонентите си. В речите си често споменава Независимостта на Аржентина и всички славни минали събития. За Аа бъле още по-убедителна, разчита на различни символи и оракти, които Аа включи. Аискурсът е нейното спасение. Ао края на мандатьт й той е важен за нея. Като истински популист непрекьснато чертае красиво бьлеще, полчертава, че периодьт на развитие е започнал при управлението на мъжа й президентьт Нестор Кирхнер. От тогава е започнала защитата на човешките права, равенството и социалната справеАливост. Това е мицето на "ЕАна различна Аржентина" ("Una Argentina diferente"). Никога не говори ^ошо за сьпруга си - нито, Аокато е жив, нито слеА това, с което още повече печели алмирациите на хората. Коментарите, които прави са прости и ясни - Аори и понякога $А$ н нямат нищо общо с залаления въпрос. (Ibarra: Cristina versus Cristina: el ocaso del relato).

\section{Аяв попумизъм}

Ао тук бяха преАставени Ава примера за ляв популизъм. Той е насочен срещу "елитите“ - политически, икономически, меАийни. По принцип с това трябва $а$ а се занимават всички меви партии. Но тралиционната мевица и като цяло съвременните социалисти и социалдемократи отАавна са прекьснали врьзката с обикновените хора. Тралиционната левица е напьлно либерализирана и маргинализирана.

\section{Аесен популизъм}

Популизмьт не е единно явление. Напоследьк все по-често продобиват популярност Аесните популистки Авижения. Страните в Запална Европа са най-добрият пример затова. Те са критично настроени кьм статуквото, но цялата ярост и негодование са насочени към чужАенците - предимно бежанците и имигрантите. Той не е явление, възникнало през послеАните години. Още през 90-те години на 
миналия век в страни като Канала, Норвегия, Франция, Израел, Полша, Русия, Румъния и Чили трайно се настаняват Аесни популистки формации в законодателните органи. В страни като Швейцария. Австрия, Нилерландия, Нова ЗеланАия и Италия - те влизат и в коалиционни правителства. Това са страни, в повечето случаи със си^но развите икономики, които изглежАат привлекателни за хората от развиващите се Аьржави. Аесният популизьм се различава от историческата десница по това, че тя се ангажира със запазването на статуквото. Интересното при Аесния популизъм е, че исторически той е създален от мъже, разчита на авторитарен и харизматичен мидер, обрьщенията са предназначени за мижете избиратели и в повечето случаи - са насочени срещу жените. Както вече беше споменато в АоклаАа, популизмът непрескъснато се променя и Анес не малко жени гласуват за такива партии. За да бълат привлечени още жени като гласоподаватеАи и симпатизанти, Анес има Аесни популистки партии с жени ^илери. Примери за това са „Национален фрронт“ във Франция, с милер Марин Аьо Пен, „Италиански братя“, с ^илер АжорАжия Мелони и Аруги. На въпроса защо не са предпочели $А$ с станат член или $А$ а полкрепят леви партии, те отговарят, че левите партии отАавна не представляват жените, оременизмьт в Европа вече е свърши^ и те могат Аа защитават, както себе си, така и останалите жени от напаление от имигранти или просто да защитават правата на майките, Аецата. Аискурсите на десните популисти са изпьлнени с омраза към всички, които не са местни, остра критика кьм управляващите, страх от фринансова криза и силен евроскептисизьм. Целта им е $а$ в внушат страх у хората и $и$ а изглежлат като герои в очите им. Тъй като популизмьт не се страхува $А$ експериментира непрекьснато с нови илеи, Анес "спасителят" е в мицето на жена.

\section{Популизмът в България}

Темата за популизма в българската политика не е полробно изслеАвана. Първите политолози, които са писали по този въпрос Георги Карасимеонов и Ааниел Смилов, посочват Симеон Сакскобургготски за пьрвия популист в страната. Неговите обещания за по-Аобър живот, запомнящата се ораза: „Вервайте ми!“, както и амбициозното обещание „Ще ви оправя за 800 Ани“ и непрекъснатите 
СНИМки среА народа, КьАето позволява на по-визрастните $А$ го наричат "Симеончо" - дават пьлното основание $а$ а бъде наречен популист.

Следващият „спасител" на българите е в мицето на Бойко Борисов. За него анализаторите твърлят, че е започнал политическата си кариера като популист: напрекъснато го дават по телевизията и го представят като герой, изявява се като футболист, "мъж-мечта". Простият му народен изказ го доближават все повече $А$ хората, повечето е припознават в него и затова гласуват. СлеАва етап, когато е по-малко популист и в момента, в който започва Аа губи от Аоверието на избирателите - се качва на Ажипа и започва да обикаля страната и Аа се прави на обикновен човек.

Някои посочват Волен Силеров като най-големият популист. Той несъмнено е такъв, макар да се колебае межлу крайнолесният - със своята антимигрантска и антиромска реторика и крайнолевият обещавайки европейски пенсии и добри отношения с Русия.

Най-новият пример за популист е Слави Трифронов. Човек, разчитащ на популярност, благодарение на телевизионното си предаване и песни, на прьв поглед звучи абсурАно $А$ а се яви на избори. Но отново, избирателите очакват своя "месия", харесва им това, което чуват и се Аоверяват.

Ако трябва $\Delta а$ се посочи българска жена популист, това е Мая Манолова. Както беше споменат по-напрел, популизмьт няма илеология. СлеА напускането й на Бьлгарската социалистическа

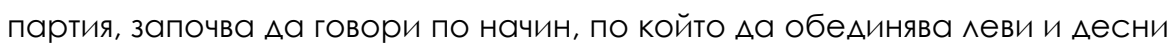
избиратели, пътува в градския транспорт, участва в различни

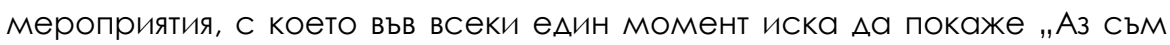
еАна от вас!".

За съжаление политическата култура в България е на много ниско ниво и наистина трябва да се появи „спасител“, който Аа вАигне малко нивото. Затова популизмьт има бълеще. Не само в Бьлгария, а и по цял свят. Защото хората навсякъАе, С малКи изключения, са разочаровани от политическите елити и се наляват на нещо поразлично и по-Аобро. И вярват на това, което чуват, защото популистите

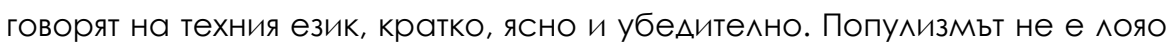
нещо. Произлиза от ^атинската дума рорulus, което означава „народ". А политиките, насочени към полобряването на живота не могат $а$ б бъдат 
^оши. Силата на популизма се изразява в неговата способност $а$ а се променя взависимост от Аьржавата, актуалните проблеми и исканията на обществото. По този начин обхваща не само безпартийните избиратели, но и разочарованите, колебаещите се, всички, които не се чувстват преАставени от настоящето правителство.

Популизмът има бъдеще по целия свят, защото проблеми възникват всеки Аен, неспособни политици иАват на власт и проблемите се зальлбочават. Популистите твьрдят, че винаги имат „верния отговор“, знаят "правилното решение" и все повече хора искат $\Delta а$ чуват тези успокоителни Ауми. СпореА Аанни на английския вестник „Гардиан" само за енно Аесетилетие броят на популистите, които участват по еАин или Аруг начин в управлението на еАна страна се е увеличи^ 14 пьти. Тази тенленция ще се засилва, докато „управляващите елити“ не се вслушат в гласа на нарола. За съжаление разстоянието межАу еАните

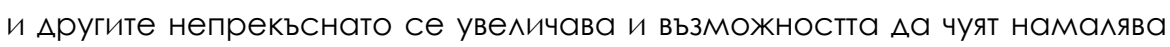
все повече. За сметка на това популистите са близо и чуват и вижлат вСичко.

\section{АИTEPATYPA / REFERENCES}

Bremmer, I. (2018). Us vs. Them: The failure of Globalism, New York: Portfolio/ Penguin

Celis, K.; Lovenduski, J. (2018). European journal of politics and gender: Power struggles: gender equality in political representation, vol. $01 /$ num. 01 - 02, Bristol: Bristol University Press, pp 149 - 166.

Childs, S.; Dahlerup, D. (2018). European journal of politics and gender: Increasing women's descriptive representation in national parliaments: the involvement and impact of gender and politics scholars, vol. 01/ num. 01 - 02, Bristol: Bristol University Press, pp $185-204$.

Clinton, H. (2017). What happened, New York: Simon and Schuster.

Dovi, S. (2018). European journal of politics and gender: Misogyny and transformations, vol. 01/ num. 01 - 02, Bristol: Bristol University Press, pp 131 - 147.

Etzioni, A. (2018). Law and society in a populist age: balancing individual rights and the common good, Bristol: Bristol University Press.

Felix, A.; Glaser, E. (2018). Triumph of the women?: The female face of the Populist and far right in Europe, Berlin: Friedrich - Ebert - Stiftung. 
Ignatova, D. (2015). Moralni aspekti na populistkite resheniya $\vee$ politikata (in Bulgarian). In: „Doktorantski sbornik 2014, doktorantski izsledvaniya $v$ sotsialnite i humanitarnite nauki", Publisher: Iztok Zapad, Sofia, Bulgaria, 2015, pp. 207-209. // [Игнатова А. Морални аспекти на популистките решения в политиката. Софрия: изА. Изток ЗапаА, 2015 в Сб: „Аокторантски сборник 2014, Аокторантски изслеАвания в социалните и хуманитарните науки", с. 207-209].

Joignant, A. (2012). Habitus, campo y capital. Elementos para una teoria general del campo politico. Mexico: Revista Mexicana de Sociologia, 2012, vol. 74, num. 4, octubre-diciembre, pp $587-618$.

Meret, S.; Siim, B. (2017). European conference on politics and gender (ECPG): A Janus - faced feminism: Gender in women - led right - wing populist parties, Lausanne: University of Lausanne.

Mudde, C.; Rovira-Kaltwasser, C. (2012). Populism and (liberal) democracy: a framework for analysis, in Populism in Europe and the Americas: Threat or Corrective for Democracy?, Cambridge: Cambridge University Press, pp 1-26.

Rico, G.; Guinjoan, M.; Anduiza, E. (2017). The emotional underpinnings of populism: how anger and fear affect populist attitudes. Swiss Political Science Review 23 (4), pp 444-461.

Sayer, A. (2016). Why we can't afford the rich, Bristol: Policy press.

Smilov, D. (2008). Populizmat kato ideologiya (in Bulgarian). In: "Politicheski izsledvaniya, 2008, br.1", Publisher: Fridrih Ebert, Sofia, Bulgaria. // [Сми^ов А. Популизмьт като илеология. София: изА. Фридрих Еберт, в Сб: Политически изслеАвания, 2008, бр.1].

Teorell, J.; Sum, P.; Tobiasen, M. (2007). Participation and political equality, in Citizen and Involvement in European Democracies. Abingdon: Routledge.

Wajner, D. (2019). Populism and world politics: Making (Latin) America great again: lessons from Populist foreign policies in the Americas, Jerusalem: The Hebrew University, pp $198-225$.

\section{Интернет източници / Internet sources:}

Marine Le Pen - $\quad$ Wikipedia

[https://bg.wikipedia.org/wiki/\%D0\%9C\%D0\%B0\%D1\%80\%D0\%B8\%D0\%BD_\%D0\%9B\%D1 \%8C\%D0\%BE \%D0\%9F\%D0\%B5\%D0\%BD, (Last view: 13.03.2020)] // [Марин ^ьо Пен Уикипелия]

Petrie,

Frauke

Wikipedia

$-$

[https://ru.wikipedia.org/wiki/\%D0\%9F\%D0\%B5\%D1\%82\%D1\%80\%D0\%B8,_\%D0\%A4\%D1\% 80\%D0\%B0\%D1\%83\%D0\%BA\%D0\%B5, (Last view: 13.03.2020)] // [Петри, Фрауке ВикипеАия]

Meloni, Giorgia - Wikipedia

[https://ru.wikipedia.org/wiki/\%D0\%9C\%D0\%B5\%D0\%BB\%D0\%BE\%D0\%BD\%D0\%B8, \%D0 \%94\%D0\%B6\%D0\%BE\%D1\%80\%D0\%B4\%D0\%B6\%D0\%B0, (Last view: 13.03.2020)] // [Мелони, АжорАжа - Википелия] 


\section{КУАТУРНО-ИСТОРИЧЕСКО НАСАЕАСТВО: \\ ОПАЗВАНЕ, ПРЕАСТАВЯНЕ, АИГИТААИЗАЦИЯ}

\section{CULTURAL AND \\ HISTORICAL \\ HERITAGE}

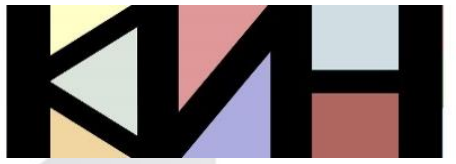

PRESERVATION PRESENTATION DIGITIZATION
Материалите в сборника са обект на авторско право. Разрешава се безвъзмезАното ползване на техни електронни/ хартиени копия само за лична употреба или обучение, при пь^но цитиране на текущата страница и слеА писмена декларация от цитиращия за Аипса на търговски намерения. За копиране пол Аруга фрорма, препубликуване или публикуване на сървъри се изисква писмено разрешение и/или заплащане.

() Авторски колектив, 2020 Техническо реАактори: Николай Ноев Калина Сотирова-Вълкова
This work is subject to copyright. Open and free of charge use of digital/hard copies of publications is granted only for personal or educational use, with full citation of the current page, and after written declaration of the quoting side for not-commercial Intention. For any other reproducing types, republishing, photocopying, recording, or any other storage retrieval system/ server written permission and/or fee is required.

(C) Authors` Group, 2020

Technical editors:

Nikolay Noev

Kalina Sotirova-Valkova

\section{Научна пореАица: том 6, брой 1 (8)/2020 Science series: vol. 6 , issue $1(8) / 2020$}

